Goldschmidt 2021 Abstract

https://doi.org/10.7185/gold2021.7100

\section{Synthesis of coloured Amorphous calcium carbonates for understanding the pigmentation mechanisms in sea urchin spines}

VASKAR SARDHALIA, TRISTAN GEORGES, THIERRY AZAÏS, MOHAMED SELMANE AND MARIE ALBERIC

Sorbonne Université

Presenting Author: vaskar.sardhalia@sorbonne-universite.fr

The wide range of colours observed in sea urchin skeletal elements, which are mainly composed of calcite and intracrystalline organic molecules, is due to the presence of a family of organic pigments, the polyhydroxylated naphthoquinone (PHNQ) molecules ${ }^{1}$.However, the pigmentation process in sea urchins is not well known. It has been previously shown that pigmentation and biomineralization pathways are likely coupled processes in sea urchins ${ }^{2}$. Biomineralization in sea urchins occurs through the deposition of amorphous calcium carbonate (ACC) minerals $^{3,4}$. Therefore, in order to better understand the role of organic pigment molecules in biomineralization mechanisms we performed bioinspired synthesis of coloured ACC and studied its crystallization.

Amorphous calcium carbonate particles were synthesized in the presence of different PHNQ molecules (Naphthazarin, Lawsone, Echinochrome A) through slow vapour diffusion in ethanol ${ }^{5}$ and fast precipitation in water ${ }^{6}$. We obtained purple, orange, light blue coloured ACCs. The coloured ACC samples were characterized by XRD, FT-IR, DSC, UV-visible spectroscopy analysis and SEM observations. In addition, the molecular interaction between the inorganic and organic part was studied by solid-state NMR. The results showed the influence of pigments on ACC stability. After crystallization, the ACCs lead to a slight change in colour leading to different coloured $\mathrm{CaCO}_{3}$ polymorphs.

[1] Vasileva, Mishchenko, Tran, Vo, Fedoreyev, S. (2021) Mar. Drugs 19, 21.

[2] Zito, Koop, Byrne, Matranga (2015) Dev. Growth Differ. 57 (7), 507-514.

[3] Politi, Arad, Klein, Weiner, Addadi(2004) Science 306 (5699), 1161-1164.

[4] Albéric, Stifler, Zou, Sun, Killian, Valencia, Mawass, Bertinetti, Gilbert, Politi(2019) Struct. Biol. X, 1, 100004.

[5] Chen, Cölfen, Antonietti, Yu, S.-H(2013) Chem. Commun. 49 (83), 9564.

[6] Zou, Bertinetti, Politi, Jensen, Weiner, Addadi, Fratzl, Habraken, W. J. E. M.(2015) Chem. Mater. 27 (12), 4237-4246.

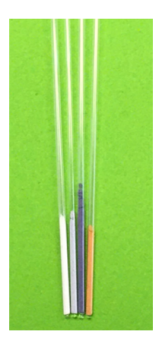
Fig: (a) Synthesised $\mathrm{CaCO} 3$ with different colours (b) powder XRD predicts the amorphous phase of the synthesized $\mathrm{CaCO} 3$.

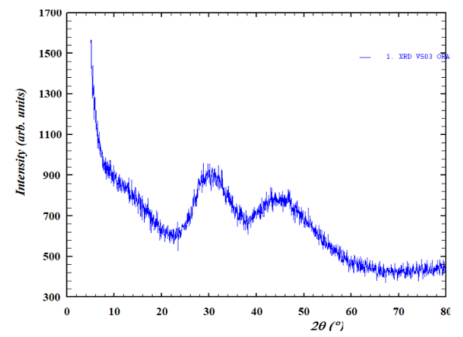

(b) 